\title{
Biomass gasification under high solar heat flux: Experiments on thermally thick samples
}

\author{
Victor Pozzobon*, Sylvain Salvador, Jean Jacques Bézian \\ Université de Toulouse, Mines Albi, centre RAPSODEE, UMR CNRS 5302, Campus Jarlard, route de Teillet, 81013 Albi CT Cedex 09, France
}

\author{
Keywords: \\ Solar power \\ Biomass \\ Gasification \\ Artificial sun \\ Experiments
}

\section{H I G H L I G H T S}

- Beech wood is exposed to radiative heat flux higher than $1000 \mathrm{~kW} / \mathrm{m}^{2}$.

- Sample geometry evolves dramatically.

- Temperature higher than $1500^{\circ} \mathrm{C}$ are reached.

- Tar yield is lowered by thermal cracking and steam reforming.

- Initial moisture content plays key role in the biomass behavior.

\section{A B S T R A C T}

In this study, thermally thick samples of beech wood are exposed to radiative heat flux above $1 \mathrm{MW} / \mathrm{m}^{2}$ (1000 suns). It was motivated by the fact that concentrated solar energy allows to achieve temperatures higher than $1200{ }^{\circ} \mathrm{C}$ where char gasification, tar thermal cracking and tar steam reforming can take place. It is achieved using a new experimental device made of an artificial sun and a new reaction chamber, that monitors the sample mass throughout a run and can trap the produced tars using a liquid nitrogen cooled tar condensing device. Thanks to this experimental device, it is possible to compute the average wood consumption rate as well as drying water, char, gas and tar production rates. The produced light gases are also analyzed using microGC. Furthermore, a radiometer is used to monitor surface temperature, which is around $1500^{\circ} \mathrm{C}$. First, a new behavior has been highlighted. Under high radiative heat flux, a char crater which mirrored incident heat flux distribution, is formed inside of the sample. Then, using this device, the impact of two major parameters was tested: wood fiber orientation relative to the solar flux and initial moisture content. Wood fiber orientation (end grain and with the grain) was shown to only have a minor impact on the production rates, gas composition and crater formation. Three initial moisture contents $(0,9$ and $55 \% \mathrm{wb})$ were tested. It was shown that increasing the sample moisture leads to direct drying steam gasification of the char produced by the pyrolysis. Moreover, steam also promotes tar steam reforming and therefore decreases the tar yield. Finally, form an energetic point of view, the dry samples can achieve an energetic conversion efficiency of $90 \%$, capturing up to $72 \%$ of the incident solar power in chemical form.

\section{Introduction}

Mankind is currently facing an increase in energy cost and a climate change problem. Its reliance on fossil fuel has to decrease in favor of renewable energy sources. Among the candidates, biomass pyro-gasification is of note. This process allows to produce carbon neutral gaseous energy vector from biomass. Yet, the transformation of biomass into an energy rich gas is a succession of complex

\footnotetext{
* Corresponding author.

E-mail address: victor.pozzobon@mines-albi.fr (V. Pozzobon).
}

phenomena. It starts with the drying of biomass [1] around $100{ }^{\circ} \mathrm{C}$, where water evaporates from the biomass. Then, pyrolysis takes place around $500^{\circ} \mathrm{C}$. This complex stage turns dry biomass into three main products: light gases (from $\mathrm{H}_{2}$ to $\mathrm{C}_{3} \mathrm{H}_{8}$ ), tars (a mixture of more than 300 molecules [2]) and char [3]. Finally, around $800{ }^{\circ} \mathrm{C}$, steam - and to a lesser extend $\mathrm{CO}_{2}$ - can oxidize char and transform it into syngas $\left(\mathrm{H}_{2}\right.$ and $\left.\mathrm{CO}\right)$. This high temperature also enables tar thermal cracking [4] and tar steam reforming [5]. The produced raw gas is therefore potentially a mix of pyrolysis gas, syngas and thermally cracked and steam reformed tars. Once cleaned, filtered or upgraded, this gas can be used in a wide variety 
of processes [6]: fuel cells [7], gas turbines [8], combustion for heat, Fisher Tropsch synthesis [9] or methanol synthesis [10]. Pyro-gasification is highly endothermic. Classically, heat is supplied by burning a fraction of the inlet biomass feed. Two main drawbacks come with this technique: the efficiency with respect to the biomass is lowered and the produced syngas is diluted by $\mathrm{N}_{2}$ if air is used to power combustion in the gasification reactor $[11,12]$

Supplying the required heat using solar energy would avoid these drawbacks. Indeed, even on a large scale, solar concentrated power plants can achieve incident heat flux higher than $1000 \mathrm{~kW} / \mathrm{m}^{2}$. Hence, it is possible to reach a temperature of $1200^{\circ} \mathrm{C}$ or higher and lead pyrolysis and gasification reactions [13].

Studies on the combination of biomass gasification and concentrated solar power have been led in the past. However, they mainly focused on reactor scale experiments and modeling. These studies have yielded more insight on the design of the reactors (fixed bed [14-17], fluidized bed [18,19], cyclonic $[9,20]$ ) and the possibilities of the technology. Two reviews are available on the subject $[21,22]$. Yet, they do not permit better understanding of biomass and solar power interaction.

The combination of solar energy and biomass still raises several questions at the sample scale. Radiative power has long been seen as a way to achieve high heating rates [23,1,24-27]. Recently, solar pyrolysis has been studied in order to assess produced char properties [13]. The study featured agglomerated wood powder pellets that were suitable to lead a thermally thin experiment, but not to understand the interaction between biomass and solar energy. Furthermore, the behavior of a thermally thick virgin piece of biomass under high solar heat flux has never been studied. Wood is an anisotropic material, thus fiber orientation relative to the incident heat flux may have an impact on the behavior of the sample. The initial moisture content may also alter the sample transformation. Indeed, char produced by biomass pyrolysis can undergo gasification if in contact with steam from drying. Moreover, tar thermal cracking [4] and tar steam reforming [5] may be favored. One could therefore expect a smaller tar yield and a higher direct raw gas production.

The aim of this article is to investigate the behavior of a thermally thick biomass sample under high solar heat flux. The biomass behavior is observed qualitatively, by examining its shape evolution, and quantitatively, by monitoring mass, gas compositions and temperatures. These measurements allow to expose a never reported before behavior as well as to draw closing mass and energy balances, providing valuable insights on the biomass solar pyro-gasification process.

\section{Material and methods}

A new experimental device was built in order to investigate the effect of the initial moisture content and of the fiber orientation on wood pyro-gasification behavior. The aim of the device is to expose thermally thick beech wood samples to radiative heat flux above $1 \mathrm{MW} / \mathrm{m}^{2}$ (1000 suns). In order to achieve such high heat flux, an artificial sun was used [28-31]. Two main parameters were varied during this study: initial moisture content and fiber orientation.

\subsection{Experimental apparatus}

Fig. 1 provides a schematic of the reaction chamber. The beech wood sample is placed in an enclosure. A quartz window placed above the sample allows the radiative power to enter the enclosure and reach the sample surface. The sample is continuously swept by nitrogen in order to prevent gas and tars released by the sample to reach and soil the quartz window. This nitrogen sweep also ensures that no oxygen is present in the device at any time.
The sweeping nitrogen then carries released gas and tars through a tar condensing system. This system is made of a liquid nitrogen cooled condenser and a cotton trap. The condenser lowers the gas temperature, allowing the tar to condensate into small droplets. These droplets are then captured by the cotton trap. The condensing device is removable. It is also possible to run experiments where tars escape from the reaction chamber. It allows for the quantification of the tar production following a procedure described further.

During a run, the whole system is weighted using a scale. Therefore, the sample mass loss can be accounted for. A pyrometer is set in such a way that it measures sample surface temperature at the focal spot (Optctra 1MB CF2 CB3, working wavelengths: $0.7-1.1 \mu \mathrm{m}$, measurement range: $600-1800{ }^{\circ} \mathrm{C}$ ). A set of three type $\mathrm{K}$ and $\mathrm{S}$ thermocouples is placed inside of the sample in order to monitor its core temperature. The repeatability of these measurements was very poor and they therefore are not reported. Finally, part of the gas escaping the condenser and the cotton trap were collected and analyzed using a microGC.

A xenon arc lamp is used as radiative power source. Its radiation is concentrated toward the sample surface using an elliptical mirror. This kind of device has long been used to emulate concentrated solar energy in terms of density and spectrum. It is often referred to as an artificial sun or solar simulator [32]. In our case, the biomass sample surface is set at the focal spot of the device. It receives about $655 \mathrm{~W}$ of Gaussian distributed radiation with a maximum above $1100 \mathrm{~kW} / \mathrm{m}^{2}$ (Fig. 2) [33].

\subsection{Samples and varied parameters}

The samples used are beech wood cylinders with a height of $5 \mathrm{~cm}$ and a diameter of $10 \mathrm{~cm}$. Such massive samples were chosen to behave as slabs during a $5 \mathrm{~min}$ run. Knowing that wood is an anisotropic material, special care was taken in choosing the wood fiber orientation. Two batches of sample were used for the experiments: a first batch of sample made of end grain wood where the wood fibers are parallel to the cylinder axis (Fig. 3a), a second made of with the grain wood where the wood fibers are perpendicular to the cylinder axis (Fig. 3b).

Sample moisture content is also a parameter that was varied in this work. Three different moisture contents were used for the experiments: $0 \% \mathrm{wb}$, oven dried until mass stabilized, $9 \% \mathrm{wb}$, water content stabilized after several month under room condition and $55 \% \mathrm{wb}$, impregnated in water until mass stabilized which is thought to be a representative state of the wood after cutting [34]. Because of the induced swelling and shrinking, the wood density varies with moisture content. The densities are $652 \pm 40$, $579 \pm 38$ and $535 \pm 8.0 \mathrm{~kg}$ of $\operatorname{wood} / \mathrm{m}^{3}$ for, respectively, 0,9 and $55 \% \mathrm{wb}$ initial moisture content samples.

\subsection{Experimental procedure}

The following steps were strictly followed for every run:

- weighting the sample, the reaction chamber, the condenser and the cotton

- cooling the condenser by immersing it in liquid nitrogen

- placing of the sample in the reaction chamber

- loading the liquid nitrogen cooled condenser and the cotton trap

- set up of the cell at the focal spot

- exposing the sample for 5 min while collecting gas sample

- cooling the sample under nitrogen sweep for 5 min

- extracting the sample

- weighting the sample, the reaction chamber, the condenser and the cotton 


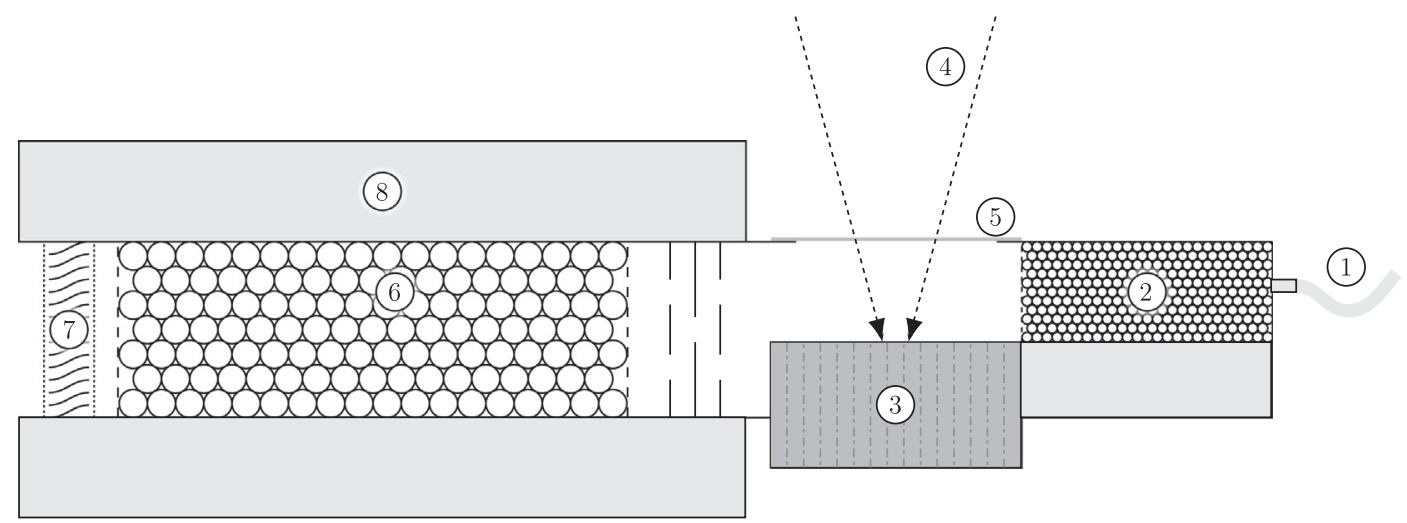

Fig. 1. Schematic of the reaction chamber. (1) Nitrogen inlet, (2) porous medium, (3) sample, (4) incident heat flux, (5) quartz window, (6) tar condensing device, (7) cotton trap, and (8) insulating material. Radiometer: not shown.

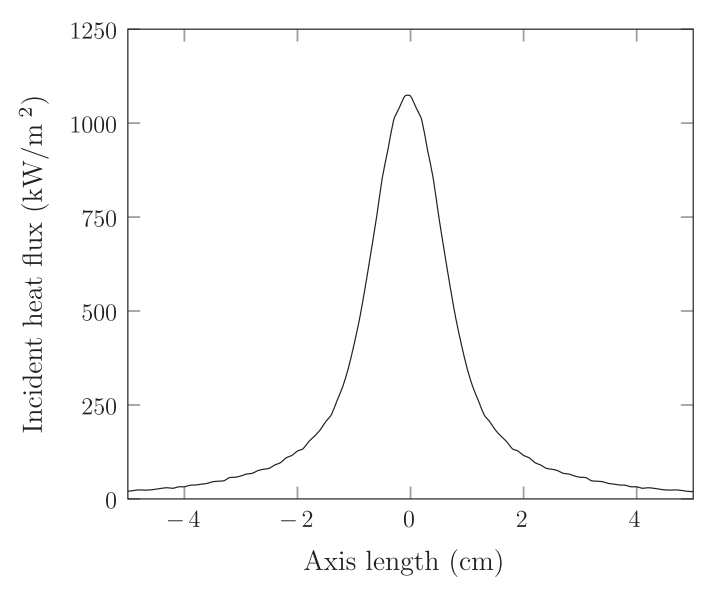

Fig. 2. Incident heat flux on the sample surface.

In order to assess for the repeatability, every runs was repeated at least three times.

\subsection{Data processing}

In order to calculate wood consumption, evaporated water, char, gas and tar average production rates, several mass measurements were taken before and after a run. Before a run, sample mass $m_{\text {sample, } i}$ and reaction chamber mass $m_{\text {chamber, } i}$ were measured. After a run, sample mass $m_{\text {sample, } f}$ and reaction chamber mass $m_{\text {chamber, } f}$ were measured again. Exposed samples contain a char residue produced by pyrolysis which was not consumed by gasification (Fig. 4). This char was scratched away from the sample and its mass $m_{\text {char }}$ was taken. Then, the void left by the char was filled with sand in order to measure the volume of the crater in the wood. The mass of this sand $m_{\text {sand }}$ was taken. Knowing, the sand bed and the wood density, it is possible using Eq. (1) to determine the mass of anhydrous wood $m_{\text {wood }}$ consumed during a run.

$m_{\text {wood }}=m_{\text {sand }} \frac{\rho_{\text {wood }}}{\rho_{\text {sand bed }}}$

Samples were exposed to radiative power in two configurations: with and without tar condensing device. During a run without tar condensing device, gas, tar and water freely escaped from the reaction chamber. Thus, the reaction chamber mass variation $\Delta m_{\text {chamber, no cond. }}$ accounts for the mass of gas produced by the sample $m_{\text {gas }}$, the mass of evaporated water from the sample $m_{\text {water }}$ and the mass of tar produced by the sample $m_{\text {tar }}$ (Eq. (2)). One should

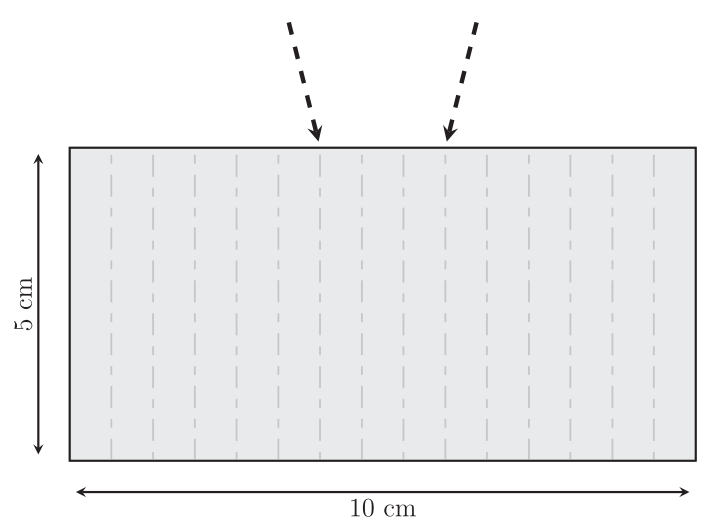

(a) End grain sample

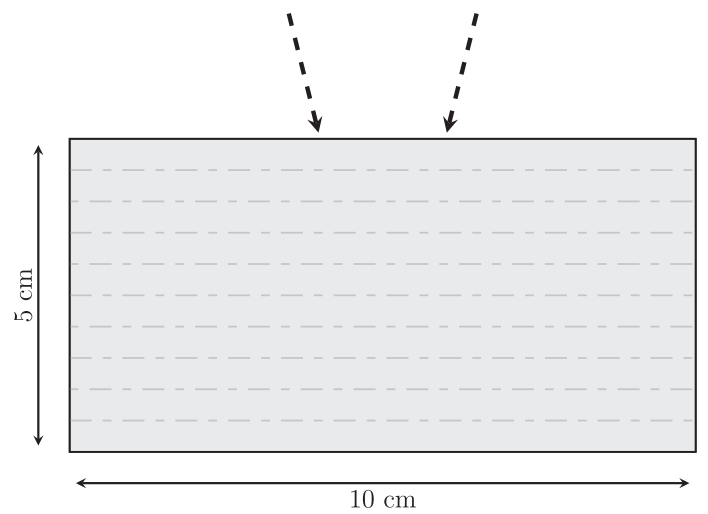

(b) With the grain sample

Fig. 3. Samples sketches.

note that, in this work, $m_{\text {tar }}$ includes the water produced by the pyrolysis [35-39] and $m_{\text {water }}$ refers only to the water coming from the drying of the sample.

$$
\begin{aligned}
\Delta m_{\text {chamber, }(\text { no cond.) }} & =m_{\text {chamber, } f \text { (no cond.) }}-m_{\text {chamber, } i \text { (no cond.) }} \\
& =m_{\text {gas }}+m_{\text {water }}+m_{\text {tar }}
\end{aligned}
$$

During a run with the tar condensing device, gas alone escapes from the reaction chamber. Thus, the reaction chamber mass variation $\Delta m_{\text {chamber, cond. }}$ only accounts for the mass of gas produced by the sample $m_{\text {gas }}$ (Eq. (3)). 


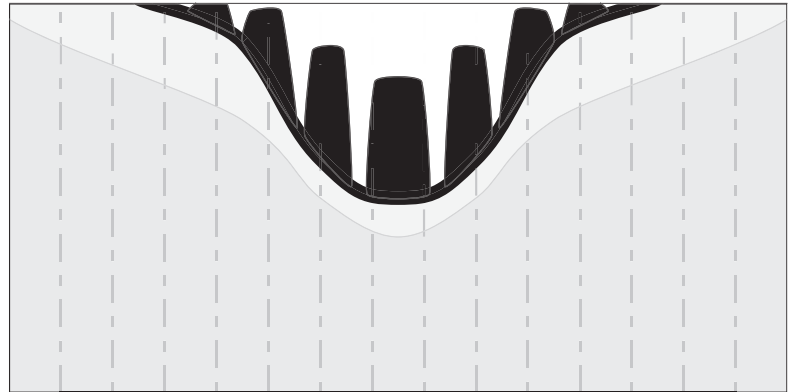

Fig. 4. Schematic cut view of a sample after exposure. Dark gray: moist wood area light gray: dry wood area, black: char residue.

$\Delta m_{\text {chamber, } \text { cond. }}=m_{\text {chamber, } f \text { (cond. })}-m_{\text {chamber, } i(\text { cond. })}=m_{\text {gas }}$

The question of the validity of the comparison between $\Delta m_{\text {chamber, no cond. }}$ and $\Delta m_{\text {chamber, cond. }}$ may arise. Indeed, these two values are not determined using the same sample. Comparing the reaction chamber mass variation in the two configurations (i.e. $\Delta m_{\text {chamber, no cond. }}$ and $\Delta m_{\text {chamber, cond. }}$ ) is possible thanks to the good repeatability of the mass signal (Fig. 5).

From these various measurements, it is possible now to determine the mass of evaporated water released by the sample

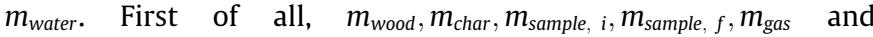
$\Delta m_{\text {chamber, no cond. }}$ are known. We now consider the sample mass variation $\Delta m_{\text {sample. }}$. It accounts for the mass loss of wood $m_{\text {wood, }}$, mass loss by drying $m_{\text {water }}$ and mass gain by char formation $m_{\text {char }}$ (Eq. (4)). It is possible to access $m_{\text {water }}$ using Eq. (4). By knowing $m_{\text {water }}$, it is now possible to access $m_{\text {tar }}$ using Eq. (5).

$\Delta m_{\text {sample }}=m_{\text {sample, } f}-m_{\text {sample }, i}=m_{\text {char }}-m_{\text {wood }}-m_{\text {water }}$

$m_{\text {tar }}=m_{\text {chamber, } f \text { (no cond. })}-m_{\text {chamber, } i \text { (no cond. })}-m_{\text {gas }}-m_{\text {water }}$

It is therefore possible to calculate the wood consumption and also drying water release, char gas and tar average production rates by dividing the masses by the total run time of $5 \mathrm{~min}$.

Furthermore, by weighting the reaction chamber during a run with the tar condensing, it is possible to determine the evolution of gas production rate.

Three gas samples were also taken at the outlet of the cotton trap at $t=0-1 \mathrm{~min}, 2-3 \mathrm{~min}$ and $4-5 \mathrm{~min}$. Gas was then analyzed using a microGC. Average gas composition was also used to

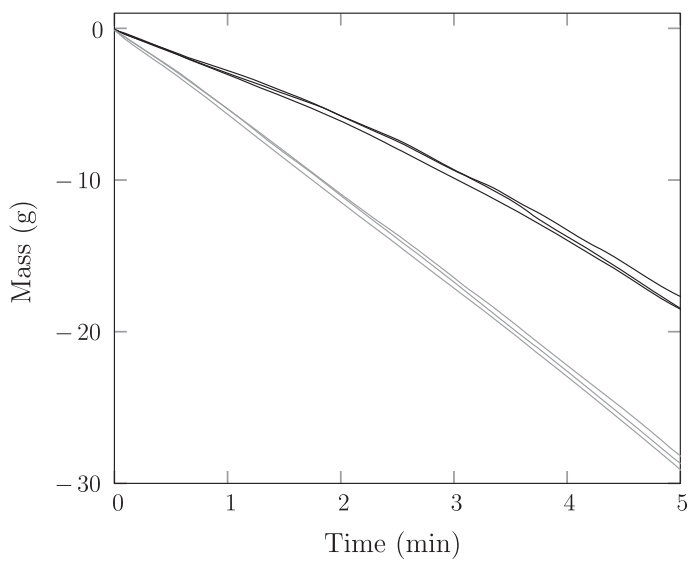

Fig. 5. Three mass signals of reference case sample ( $9 \% \mathrm{wb}$, end grain). Black: with tar condensing device (stopping tar and water), gray: without tar condensing device. calculate the average gas production rate. Indeed, knowing the nitrogen flow rate from the mass flow meter and the stream composition, it is possible to compute the average gas flow rate.

\section{Results}

\subsection{Reference case processing}

The case processing is here extensively described for the reference case: end grain $9 \% \mathrm{wb}$.

Fig. 6 shows the sample after a 5 min exposure to radiation. A complex geometry has developed. On the top view, one can see a fractured design showing alternatively empty canyons and char rods. The cut view highlights the presence of a charred area with a crater shape. This shape corresponds to the incident heat flux distribution. This crater is filled with standing char rods as illustrated in Fig. 4.

On average, wood consumption rate is $5.76 \mathrm{~g} / \mathrm{min}$ (Table 1 ). It is mainly transformed into gas $(3.65 \mathrm{~g} / \mathrm{min})$ and char $(1.37 \mathrm{~g} / \mathrm{min})$. The production of tar is quite low with only $9 \%(0.50 \mathrm{~g} / \mathrm{min})$ of the wood being turned into tar. This low tar yield is later explained by tar thermal cracking and steam reforming.

Gas readings show a good repeatability from run to run. Fig. 7 reports $\mathrm{N}_{2}$ free gas composition during a run. One can see that $\mathrm{H}_{2}$ and $\mathrm{CH}_{4}$ fractions remain constant throughout a run, while $\mathrm{CO}$ fraction decreases from $44 \%$ to $36 \%$ and $\mathrm{CO}_{2}$ fraction increases from $5 \%$ to $17 \%$. The explanation for the observed trends in term of gas composition is not straightforward because both tar cracking and tar reforming reactions may participate to the process. Thus, it is beyond the scope of this paper. Other species $\left(\mathrm{C}_{2} \mathrm{H}_{2}, \mathrm{C}_{3} \mathrm{H}_{8}, \mathrm{C}_{2} \mathrm{H}_{6}\right.$ and $\left.\mathrm{C}_{2} \mathrm{H}_{4}\right)$ present in the gas were measured. Their fractions remain stable during a run. The averaged gas production rate was computed from average gas composition. The obtained values

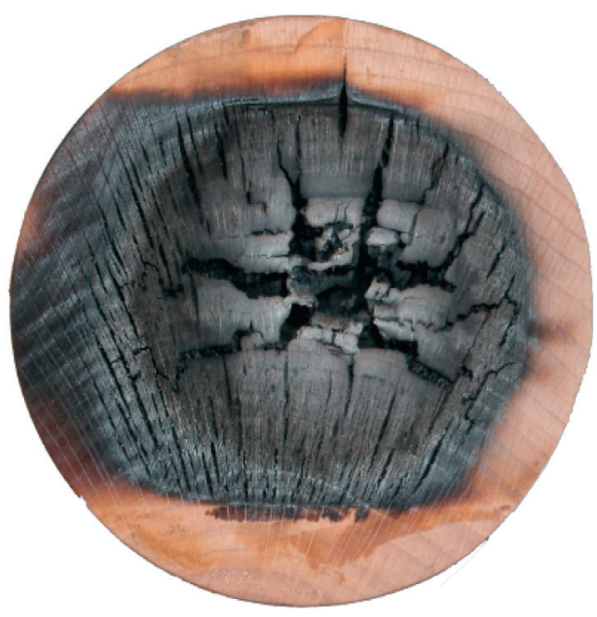

(a) Top view

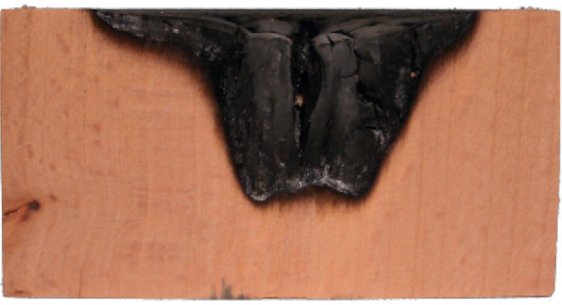

(b) Cut view

Fig. 6. $9 \% \mathrm{wb}$ moisture content end grain sample after a 5 min exposure. 
Table 1

Time averaged wood consumption, water, char, gas and tar production rates and average surface temperature for the six configurations.

\begin{tabular}{|c|c|c|c|c|c|c|c|}
\hline & & \multicolumn{5}{|c|}{ Time averaged rate $(\mathrm{g} / \mathrm{min})$} & \multirow[t]{2}{*}{ Temperature $\left({ }^{\circ} \mathrm{C}\right)$} \\
\hline & & Wood & Water & Char & Gas & Tar & \\
\hline \multirow[t]{3}{*}{ End grain } & $0 \% w b$ & $7.05 \pm 0.48$ & $0.49 \pm 0.49$ & $1.74 \pm 0.002$ & $4.12 \pm 0.07$ & $1.63 \pm 0.88$ & $1594 \pm 123$ \\
\hline & $9 \% w b$ & $5.76 \pm 0.42$ & $1.57 \pm 0.43$ & $1.37 \pm 0.002$ & $3.65 \pm 0.07$ & $0.50 \pm 0.82$ & $1530 \pm 120$ \\
\hline & $55 \% w b$ & $0.99 \pm 0.02$ & $5.89 \pm 0.06$ & $0.09 \pm 0.002$ & $1.70 \pm 0.55$ & $-0.87 \pm 0.93$ & $1317 \pm 98$ \\
\hline \multirow[t]{3}{*}{ With the grain } & $0 \% w b$ & $7.09 \pm 0.48$ & $0.06 \pm 0.49$ & $1.48 \pm 0.002$ & $3.64 \pm 0.19$ & $1.84 \pm 0.98$ & $1616 \pm 46$ \\
\hline & $9 \% w b$ & $5.68 \pm 0.42$ & $1.09 \pm 0.42$ & $1.38 \pm 0.002$ & $3.58 \pm 0.23$ & $0.49 \pm 0.83$ & $1605 \pm 90$ \\
\hline & $55 \% w b$ & $1.49 \pm 0.03$ & $2.57 \pm 0.04$ & $0.17 \pm 0.002$ & $1.94 \pm 0.20$ & $-0.80 \pm 0.98$ & $1426 \pm 20$ \\
\hline
\end{tabular}

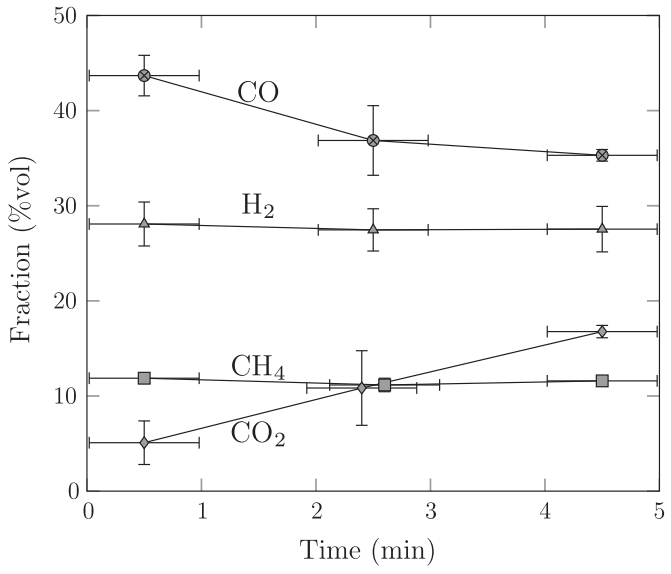

Fig. 7. Gas composition downstream the tar condensing device for the reference case ( $9 \% \mathrm{wb}$, end grain). Triangle: $\mathrm{H}_{2}$, circle: $\mathrm{CO}$, diamond: $\mathrm{CO}_{2}$, square: $\mathrm{CH}_{4}$.

are $10 \%$ close to the one obtained using mass measurements. It is thought to be a very satisfactory agreement.

Surface temperature measurements exhibit the same trend (Fig. 8) when repeating the experiment. During the first few seconds of the run, the reading exhibits an overshoot. This overshoot is explained by the high reflectivity of virgin wood around 63\% [40] that blinds the radiometer with reflected light from the Xenon arc lamp. Once the surface is charred, the reflectivity drops to near zero and allows for a proper measurement of the surface temperature. During a run, surface temperature is around $1530^{\circ} \mathrm{C}$, with a slightly downward trend. Between runs, $\pm 120^{\circ} \mathrm{C}$ variations are observed. It is known from literature that temperatures higher than $800{ }^{\circ} \mathrm{C}$ are required to achieve tar thermal cracking [41] and

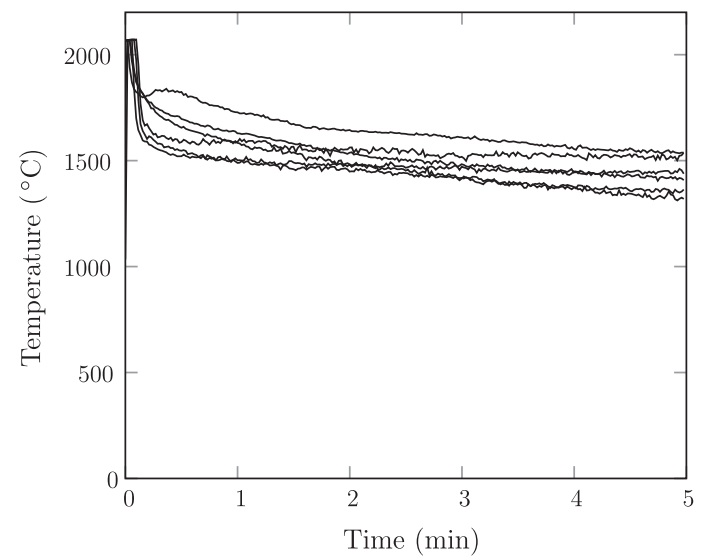

Fig. 8. Surface temperature for $9 \%$ wb initial moisture content end grain samples. tar steam reforming [42]. Here, the surface temperature is much higher than $800^{\circ} \mathrm{C}$, making tar thermal cracking and tar steam reforming kinetically favored.

\subsection{Crater formation}

Cut views of 9 and $55 \% w b$ initial moisture content samples in both fiber directions are reported in Fig. 9. The $0 \% \mathrm{wb}$ initial

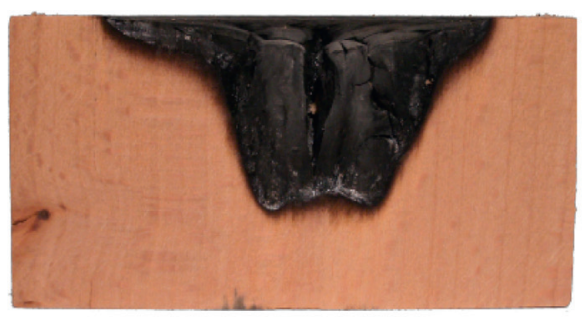

(a) $9 \% \mathrm{wb}$, end grain

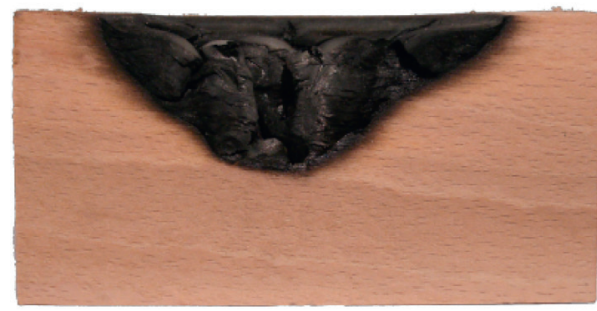

(b) $9 \% \mathrm{wb}$, with the grain

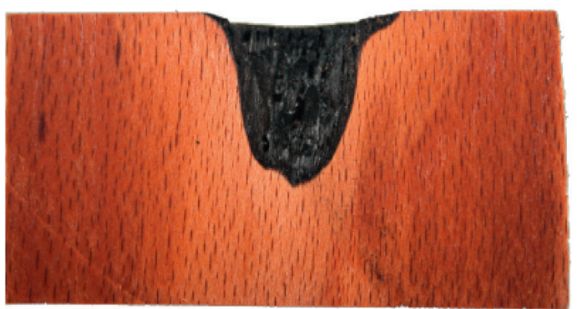

(c) $55 \% \mathrm{wb}$, end grain

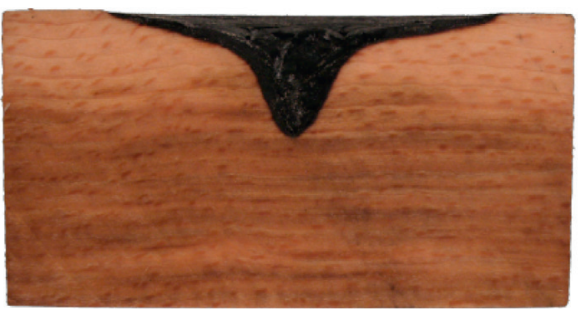

(d) $55 \% \mathrm{wb}$, with the grain

Fig. 9. Samples cut views after 5 min exposure. 
moisture content samples cut views are not reported because they are very close to those of $9 \% \mathrm{wb}$ initial moisture content samples. During a run, sample geometry is significantly modified. Two main behaviors emerge from these observations. For low initial water content samples, char rods stand inside the crater. For high initial water content samples, a smaller crater is formed, yet no rods stand inside of it. Moreover, cut views show that the transition between wood and char is very sharp. It is therefore possible to consider that the sides of the crater are in fact the location of a pyrolysis front.

- In the case of low initial moisture content, wood shrinking and mechanical failure are thought be at the origin of the char rods formation. Indeed, it is known that during pyrolysis wood shrinks as it turns into char loosing about $70 \%$ of its initial volume $[40,43]$. In this case, under the high radiative heat flux, the medium undergoes pyrolysis and starts shrinking. As the mechanical constraint grows, some weak spots in the wood structure break. These breaks yield char rods on one hand and canyons on the other. Then the canyons allow the radiation to penetrate even further inside of the sample, providing energy for in depth pyrolysis. In the end, this mechanism yields a crater zone which has a shape close to incident heat flux distribution. Moreover, it is possible using the cut view pictures to determine the pyrolysis front thickness. The front thickness is about $3 \mathrm{~mm}$ for $9 \% \mathrm{wb}$ sample and $4 \mathrm{~mm}$ for $0 \% \mathrm{wb}$ samples.

- In the case of high initial moisture content, steam coming from drying is thought to play a major role in the geometrical evolution of the sample. In the case of low initial moisture content samples, the amount of water released by drying is not high enough to allow for complete char gasification. For high initial moisture content samples, the drying provides enough steam to gasify the char produced by the pyrolysis. Indeed, in order to escape from the sample, the steam has to go through the char which is at temperature far higher than $800^{\circ} \mathrm{C}$. Therefore, char undergoes steam gasification which explains why no char rods are found inside of the crater. Furthermore, the pyrolysis front thickness is small, about $0.5 \mathrm{~mm}$. Indeed, pyrolysis is thought to be shortly preceded by a drying front and is closely followed by a gasification front which immediately consumes the char produced by the pyrolysis front.

There are also similarities in the crater shapes between end grain and with the gain samples (Fig. 9). In the case of $9 \% \mathrm{wb}$ initial moisture samples, the char rods inside of the crater are standing upward in both cases. This is surprising given the fact that in the end grain cases, the wood fibers are orthogonal to the incident heat flux. One can also note that the average diameter of the char rods is more important in with the grain samples. Nevertheless, some minor discrepancies remain. End grain samples exhibit a deeper and narrower crater than with the grain samples. This is due to the fact that wood is an anisotropic material. In the end grain cases, the fiber orientation favors heat conduction towards the bottom of the crater inducing sharper shapes. In the with the grain cases, the fiber orientation favors heat conduction towards the sides of the crater inducing flatter shapes.

\subsection{Impact of fiber orientation}

Sample fiber orientation varies between two extreme configurations: end grain (vertical fibers) and with the grain (with horizontal fibers). This difference was expected to have an impact on the global behavior of the samples because wood is an anisotropic material. Indeed, the ratio of longitudinal to radial thermal conductivity is about 2 [44]. Furthermore, the ratio of the permeability in the same directions is about five thousands [45].

Fig. 10 allows for a direct confrontation of the production/consumption rates between the two fiber orientations (data can be found in Table 1). The wood consumption, drying water release, gas, tar and char production rates exhibit close values with only one exception for the $55 \% \mathrm{wb}$ cases. In this particular case, water released is much higher for vertical fibers samples than for horizontal ones. It can be explained by the fact that these saturated samples naturally dry in air. Indeed, the channels of the wood come out directly on a pure nitrogen sweeping flow. This setup dramatically promotes drying. In the case of end grain samples, the channels of the wood come out on the side of the sample, where there is no sweep. The discrepancy between end grain and with the grain water release rate for $55 \% \mathrm{wb}$ samples is explained by a more efficient drying. This was checked in special experiments where sample were expose to the nitrogen sweep without radiative heating.

Fig. 11 reports the fractions of the major components of the gas at the outlet of the tar condensing device (data can be found in Table 2). The gas compositions for two fiber orientations are very close for $\mathrm{CO}, \mathrm{CO}_{2}$ and $\mathrm{CH}_{4}$. The fraction of $\mathrm{H}_{2}$ may seem to be slightly more important for with the grain samples, yet, given the uncertainty, no solid conclusion can be drawn. The same can be stated for gas minor components (Table 3 ).

Finally, average surface temperatures are very close for end grain and with the grain configurations (Table 1).

\subsection{Impact of initial moisture content}

The comparison between consumption/production rates with different initial moisture contents is not direct. For instance, the amount of gas produced by a high initial moisture sample is lower than for an initially dry sample. Yet, the amount of converted wood is not the same between these two. In order to solve this problem, the wood consumption rate was chosen as the

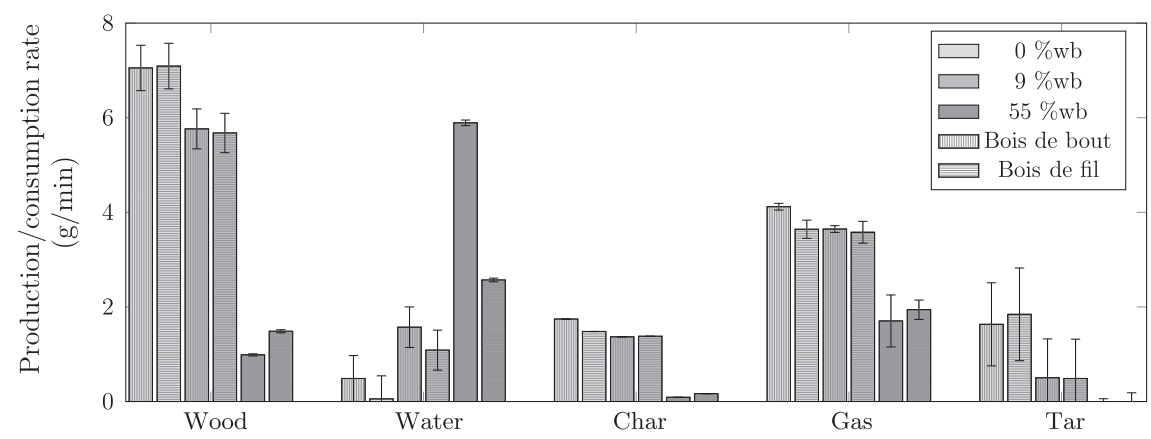

Fig. 10. Production/consumption rates for the six configurations. 


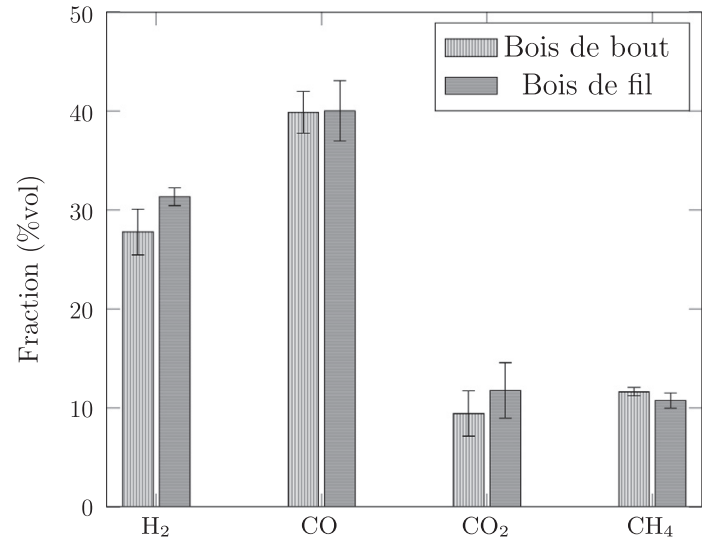

Fig. 11. Major components of the gas for $9 \% \mathrm{wb}$ moisture content samples. Dark gray: end grain, light gray: with the grain.

Table 2

Fractions of major components in the $\mathrm{N}_{2}$ free gas at the outlet of the tar condensing device averaged throughout a run.

\begin{tabular}{|c|c|c|c|c|c|}
\hline & & \multicolumn{4}{|c|}{ Fraction (vol\%) } \\
\hline & & $\mathrm{H}_{2}$ & $\mathrm{CO}$ & $\mathrm{CO}_{2}$ & $\mathrm{CH}_{4}$ \\
\hline \multirow{3}{*}{ End grain } & $0 \% \mathrm{wb}$ & $25.85 \pm 2.06$ & $43.16 \pm 2.37$ & $11.09 \pm 2.59$ & $13.22 \pm 0.53$ \\
\hline & $9 \% w b$ & $27.79 \pm 2.31$ & $39.88 \pm 2.13$ & $9.45 \pm 2.29$ & $11.63 \pm 0.44$ \\
\hline & $55 \% w b$ & $37.81 \pm 3.42$ & $30.95 \pm 3.12$ & $12.15 \pm 2.41$ & $8.47 \pm 0.95$ \\
\hline \multirow{3}{*}{$\begin{array}{l}\text { With the } \\
\text { grain }\end{array}$} & $0 \% \mathrm{wb}$ & $30.52 \pm 3.32$ & $40.53 \pm 1.17$ & $11.23 \pm 2.01$ & $11.23 \pm 0.49$ \\
\hline & $9 \% w b$ & $31.35 \pm 0.89$ & $40.01 \pm 3.04$ & $11.78 \pm 2.81$ & $10.76 \pm 0.75$ \\
\hline & $55 \% w b$ & $36.83 \pm 1.69$ & $33.42 \pm 2.36$ & $13.51 \pm 2.13$ & $8.71 \pm 0.53$ \\
\hline
\end{tabular}

Table 3

Fractions of minor components in the $\mathrm{N}_{2}$ free gas at the outlet of the tar condensing device averaged throughout a run.

\begin{tabular}{llllll}
\hline \multicolumn{5}{c}{ Fraction (vol\%) } \\
\cline { 3 - 6 } & & $\mathrm{C}_{2} \mathrm{H}_{2}$ & $\mathrm{C}_{3} \mathrm{H}_{8}$ & $\mathrm{C}_{2} \mathrm{H}_{6}$ & $\mathrm{C}_{2} \mathrm{H}_{4}$ \\
\hline End grain & $0 \% \mathrm{wb}$ & $1.69 \pm 0.48$ & $0.31 \pm 0.13$ & $0.34 \pm 0.05$ & $2.73 \pm 0.29$ \\
& $9 \% \mathrm{wb}$ & $1.41 \pm 0.28$ & $0.27 \pm 0.08$ & $0.26 \pm 0.06$ & $2.29 \pm 0.31$ \\
& $55 \% \mathrm{wb}$ & $1.70 \pm 0.38$ & $0.03 \pm 0.02$ & $0.11 \pm 0.02$ & $1.80 \pm 0.32$ \\
With the grain & $0 \% \mathrm{wb}$ & $1.33 \pm 0.19$ & $0.20 \pm 0.08$ & $0.32 \pm 0.05$ & $2.26 \pm 0.39$ \\
& $9 \% \mathrm{wb}$ & $1.58 \pm 0.51$ & $0.22 \pm 0.11$ & $0.29 \pm 0.04$ & $2.08 \pm 0.20$ \\
& $55 \% \mathrm{wb}$ & $1.65 \pm 0.26$ & $0.10 \pm 0.05$ & $0.20 \pm 0.03$ & $1.97 \pm 0.12$ \\
\hline
\end{tabular}

reference. The water, char, gas and tar production rates were divided by the wood consumption rate, giving yields on dry wood basis (Table 4).

Firstly, as one can see from Table 4, the closure of the mass balance is between $88 \%$ and $106 \%$ which is quite good. Then, as stated before, fiber orientation induces only minor variations in terms of production/consumption rates. Fig. 12 reports the relative production yields for with the grain samples; two main trends emerge from these results:

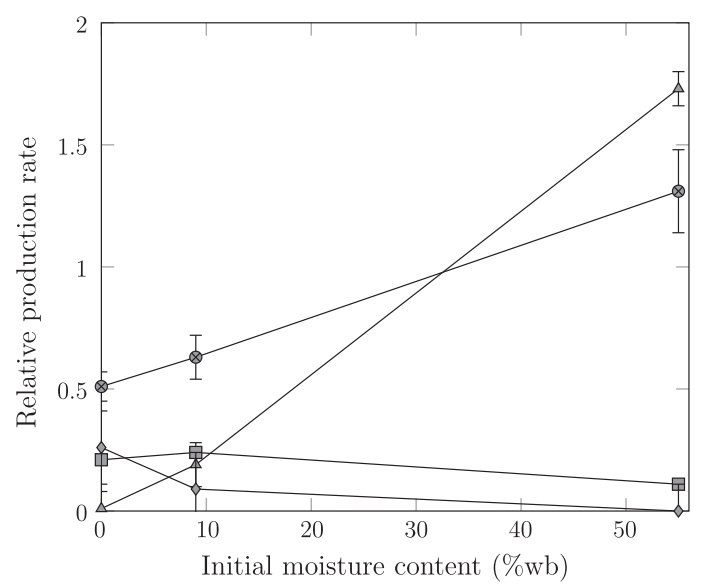

Fig. 12. Relative production rate for with the grain samples over the range of initial moisture content. Triangle: drying water, square: char, circle: gas, diamond: tar.

- An increase in sample initial moisture content leads to a significant reduction of tar production. For $0 \% \mathrm{wb}$ initial moisture content samples, about $25 \%$ of the wood is transformed into tar, whereas the tar yield is only $9 \%$ for $9 \%$ wb initial moisture content samples. Tar steam reforming is thought to play a role in this reduction. Indeed, both tar and steam have to escape the medium passing through the crater where temperature are high enough to promote tar steam reforming.

- An increase in sample initial moisture content leads to a major increase in gas production. The gas yield even exceeds 1 for $55 \%$ wb initial moisture content samples. This means that the produced gas mass exceeds the consumed wood mass. It is possible if steam contributes to gas mass through char steam gasification, tars or methane steam reforming.

The reported tar production rates are negative for $55 \% \mathrm{wb}$ initial moisture content samples (Table 1). The error associated with these measurements is quite high. Two observations are to be added. It has been qualitatively observed that tar production during these runs is actually very low. Indeed, at the end of these runs the tar condensing device contains only water; no sign of tar can be found in it. Furthermore, the tar cotton trap is superficially colored in light brown, suggesting that only few tars were produced and trapped.

As one can see in Fig. 13, gas composition varies with sample initial moisture content. Given the error bars, it is possible to consider that 0 and $9 \% \mathrm{wb}$ initial moisture content gases have the same composition. Increasing the initial moisture content to $55 \%$ wb leads to an increase in $\mathrm{H}_{2}$ fraction from 26 to $38 \mathrm{vol} \%$, a decrease in $\mathrm{CO}$ and $\mathrm{CH}_{4}$ fractions from 43 to $31 \mathrm{vol} \%$ and from 13 to $8.5 \mathrm{vol} \%$ respectively, while $\mathrm{CO}_{2}$ fractions remains stable. Yet, one should note that the relative gas mass production dramatically increases at the same time. The rise in $\mathrm{H}_{2}$ production is thought to be associated with syngas production by steam gasification of char.

Table 4

Time averaged yields on dry wood basis and mass closure.

\begin{tabular}{|c|c|c|c|c|c|c|}
\hline & & Water & Char & Gas & Tar & Closure (\%) \\
\hline \multirow[t]{3}{*}{ End grain } & $0 \% w b$ & $0.07 \pm 0.07$ & $0.25 \pm 0.02$ & $0.58 \pm 0.05$ & $0.23 \pm 0.14$ & 106 \\
\hline & $9 \% w b$ & $0.27 \pm 0.09$ & $0.24 \pm 0.02$ & $0.63 \pm 0.06$ & $0.09 \pm 0.15$ & 96 \\
\hline & $55 \% w b$ & $5.97 \pm 0.20$ & $0.09 \pm 0.01$ & $1.73 \pm 0.60$ & $-0.89 \pm 0.93$ & 105 \\
\hline \multirow[t]{3}{*}{ With the grain } & $0 \% w b$ & $0.01 \pm 0.07$ & $0.21 \pm 0.01$ & $0.51 \pm 0.06$ & $0.26 \pm 0.16$ & 98 \\
\hline & $9 \% w b$ & $0.19 \pm 0.09$ & $0.24 \pm 0.02$ & $0.63 \pm 0.09$ & $0.09 \pm 0.15$ & 96 \\
\hline & $55 \% w b$ & $1.73 \pm 0.07$ & $0.11 \pm 0.01$ & $1.31 \pm 0.17$ & $-0.54 \pm 0.65$ & 88 \\
\hline
\end{tabular}




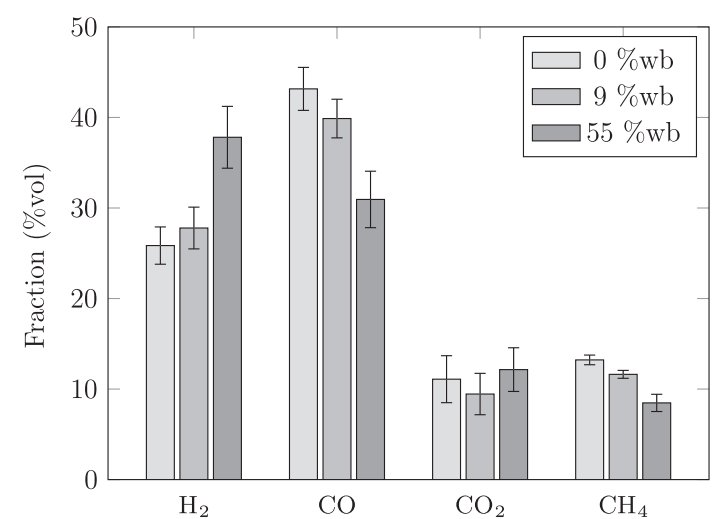

Fig. 13. Major components of the gas for 0,9 and $55 \%$ wb moisture content end grain samples.

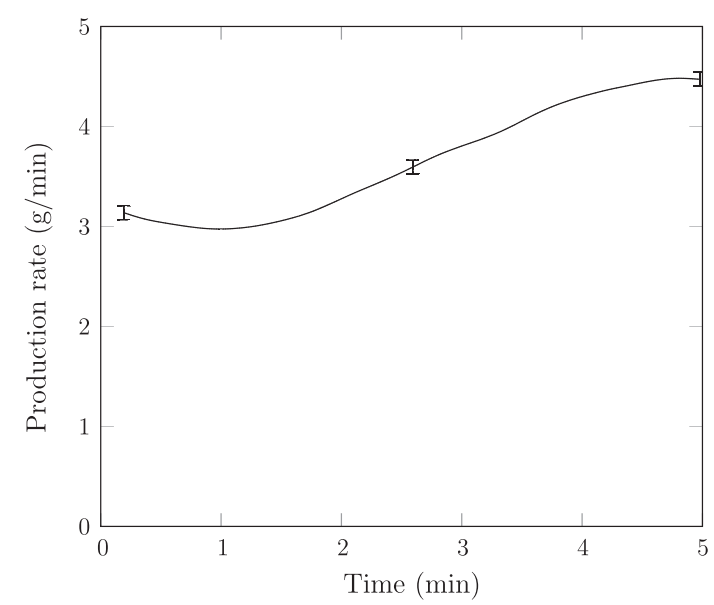

Fig. 14. Gas production rate for the reference case sample ( $9 \% \mathrm{wb}$, end grain).

Finally, average surface temperatures drops from about $1600^{\circ} \mathrm{C}$ to $1300{ }^{\circ} \mathrm{C}$ as biomass initial water content increases from 0 to $55 \%$ $\mathrm{wb}$ (Table 1). This is thought to be a consequence of the char steam gasification. Indeed, as char gasification is an endothermic reaction, it can therefore lower the medium temperature.

\subsection{Gas production over time}

Until now, we only considered time averaged value over a run. The experimental device allows to go one step further and study the gas production rate with time. Gas production rates for the reference case is available in Fig. 14. Gas production clearly increases with time. It is thought that as the char crater grows the residence time of tars inside of it increases. Therefore, the contact time between steam and tar before quenching by nitrogen sweep increases, favoring tar thermal cracking and tar steam reforming leading to gas formation.

\subsection{Energy balance}

Considering that at the process scale, gas, tar and char are the recoverable output energy carriers; it is interesting to evaluate the fraction of the input energy these products can contain. We consider the two energy inputs - incident radiative power and chemical power contained in wood - and the three energy outputs - chemical powers contained in gas, tar and char. It is possible to calculate the power contained in the chemical species flows using their HHV. Wood, tar and char HHVs were taken form the literature with values of $19.0,19.0$ and $32.1 \mathrm{MJ} / \mathrm{kg}$ respectively [46-48]. Gas HHV was calculated based on its composition (Tables 2 and 3 ). Table 5 provides the values of the input power sources and the three outputs powers for the six configurations. One can see that the total power contained in the outputs ranges as high as $94 \%$ for dry samples down to $59 \%$ for high initial moisture content samples. Gas contain about $40 \%$ of the input power in any of the configurations. For high initial moisture content, the retained power is only around half of the input power. It is indeed hindered by drying endothermicity. Nevertheless, one should note that in an industrial process, steam or hot water could be produced in heat exchangers when the producer gas is cooled down, hence increasing the energetic efficiency of the system. From a more general perspective, process integration would allow to increase the reported laboratory scale energetic efficiency $[49,50]$.

For the six configurations, the total power contained in the outputs is higher than the wood input power alone, meaning that

Table 5

Power distribution (in W) between inputs and chemical outputs. All percentages are on a total power input basis (radiative + wood).

\begin{tabular}{|c|c|c|c|c|c|c|c|}
\hline & & Radiative input & Wood HHV input & HHV output in gas & HHV output in tar & HHV output in char & Total HHV output (\%) \\
\hline \multirow[t]{3}{*}{ End grain } & $0 \% w b$ & 655 & 2233 & $1254[43 \%]$ & 517 [18\%] & 933 [32\%] & 94 \\
\hline & $9 \% w b$ & 655 & 1825 & 1137 [46\%] & $159[6 \%]$ & 732 [30\%] & 82 \\
\hline & $55 \% w b$ & 655 & 312 & $529[55 \%]$ & - & $49[5 \%]$ & 60 \\
\hline \multirow[t]{3}{*}{ With the grain } & $0 \% w b$ & 655 & 2246 & $1095[38 \%]$ & 584 [20\%] & $792[27 \%]$ & 85 \\
\hline & $9 \% w b$ & 655 & 1798 & $1066[43 \%]$ & $154[6 \%]$ & 738 [30\%] & 80 \\
\hline & $55 \% w b$ & 655 & 470 & $576[51 \%]$ & - & $89[8 \%]$ & 59 \\
\hline
\end{tabular}

Table 6

Stored radiative power in the system outputs.

\begin{tabular}{|c|c|c|c|c|c|c|}
\hline & & Radiative input (W) & Wood HHV input (W) & Total HHV output (W) & $\begin{array}{l}\text { Converted radiative } \\
\text { power }(\mathrm{W})\end{array}$ & $\begin{array}{l}\text { Converted radiative } \\
\text { power fraction (\%) }\end{array}$ \\
\hline \multirow[t]{3}{*}{ End grain } & $0 \% w b$ & 655 & 2233 & 2704 & 471 & 72 \\
\hline & $9 \% w b$ & 655 & 1825 & 2028 & 203 & 31 \\
\hline & $55 \% w b$ & 655 & 312 & 578 & 266 & 41 \\
\hline \multirow[t]{3}{*}{ With the grain } & $0 \% \mathrm{wb}$ & 655 & 2246 & 2471 & 225 & 34 \\
\hline & $9 \% w b$ & 655 & 1798 & 1958 & 160 & 24 \\
\hline & $55 \% w b$ & 655 & 470 & 665 & 195 & 30 \\
\hline
\end{tabular}


a fraction of the incident radiative power was converted into chemical form. The amount of converted radiative power is calculated by subtracting the wood HHV input from the total HHV output. Table 6 reports the amount of radiative power retained by the system outputs. The fraction of the input radiative power converted into chemical form ranges from $24 \%$ for $9 \% \mathrm{wb}$, with the grain samples to $72 \%$ for $0 \% \mathrm{wb}$, end grain samples.

\section{Conclusion and perspectives}

Thermally thick beech wood samples were exposed to radiative heat flux comparable to the ones found in solar power towers. To do so, a new experimental device was built. It allowed to investigate for behavior of the biomass under heat fluxes higher than 1000 suns.

First, an original behavior has been highlighted. Under high radiative heat flux, sample geometry evolves dramatically during a run. A crater which mirrors incident heat flux distribution is formed. Two mechanisms of crater formation have been proposed: one involving sample shrinking and mechanical failure for low initial water content sample, then other relying on char steam gasification for high initial water content samples.

Then the effect of wood fiber orientation relative to the incident heat flux was questioned. Samples in end grain and with the grain woods were used to address this question. Surprisingly, the produced results show that varying the sample orientation between these two extrema has only a minor effect on the sample behavior.

The influence of the sample initial moisture content was investigated. It was highlighted that samples containing high initial water content undergo char gasification. They produce 2.6 times more gas than low initial moisture content samples. Furthermore, this gas is richer in $\mathrm{H}_{2}-36 \mathrm{vol} \%$ instead of $26 \mathrm{vol} \%$. Nevertheless, the input power retained in the products is quite low, around $59 \%$. The tar yield is close to zero. It has also been shown that samples containing no water produce much more tar than moist samples. Furthermore, solar pyro-gasification of dry samples exhibits a very good energy conversion efficiency: the recoverable products contain $90 \%$ of the input powers (solar + wood), capturing up to $72 \%$ of the incident solar power in chemical form.

It can be concluded that the solar pyro-gasification of moist biomass is interesting for enhanced direct $\mathrm{H}_{2}$ production with reduced tar yield, while solar pyro-gasification of dry biomass is advantageous in the perspective of solar to fuel (gas and tar) conversion.

\section{Acknowledgements}

This work was funded by the French "Investments for the future" program managed by the National Agency for Research under contract ANR-10-LABX-22-01. We would also like to thank Mickael Ribeiro and Denis Marty for their technical support.

\section{References}

[1] Galgano A, Di Blasi C. Modeling the propagation of drying and decomposition fronts in wood. Combust Flame 2004;139(1-2):16-27. http://dx.doi.org/ $\underline{10.1016 / j \text {. combustflame.2004.07.004. }}$ www.sciencedirect.com/science/article/pii/S0010218004001488>

[2] Branca C, Giudicianni P. Di Blasi C. GC/MS characterization of liquids generated from low-temperature pyrolysis of wood. Ind Eng Chem Res 2003;42 (14):3190-202. wOS:000183991400003

[3] Di Blasi C. Combustion and gasification rates of lignocellulosic chars. Prog Energy Combust Sci 2009;35(2):121-40. http://dx.doi.org/10.1016/i.pecs. $\underline{2008.08 .001 . ~}$ S0360128508000440>

[4] Milne TA, Abatzoglou N, Evans RJ. Biomass gasifier tars: their nature, formation, and conversion, vol. 57. CO: National Renewable Energy Laboratory Golden; 1998.
[5] Zhao B, Zhang X, Chen L, Qu R, Meng G, Yi X, et al. Steam reforming of toluene as model compound of biomass pyrolysis tar for hydrogen. Biomass Bioenergy 2010;34(1):140-4. http://dx.doi.org/10.1016/j.biombioe.2009.10.011. <http:// www.sciencedirect.com/science/article/pii/S0961953409002141>.

[6] Butterman $\mathrm{HC}$, Castaldi $\mathrm{MJ} . \mathrm{CO}_{2}$ as a carbon neutral fuel source via enhanced biomass gasification. Environ Sci Technol 2009;43(23):9030-7. http://dx.doi. org/10.1021/es901509n.

[7] Suwanwarangkul R, Croiset E, Entchev E, Charojrochkul S, Pritzker MD, Fowler MW, et al. Experimental and modeling study of solid oxide fuel cell operating with syngas fuel. J Power Sources 2006;161(1):308-22. http://dx.doi.org/ 10.1016/i.jpowsour.2006.03.080. <http://www.sciencedirect.com/science/ article/pii/S0378775306005866>.

[8] Morris M, Waldheim L. Energy recovery from solid waste fuels using advanced gasification technology. Waste Manage 1998;18(6-8):557-64. http://dx.doi. org/10.1016/S0956-053X(98)00146-9. www.sciencedirect.com/science/article/pii/S0956053X98001469>.

[9] Zedtwitz P, Steinfeld A. The solar thermal gasification of coal-energy conversion efficiency and CO2 mitigation potential. Energy 2003;28 (5):441-56. http://dx.doi.org/10.1016/S0360-5442(02)00139-1. <http:// www.sciencedirect.com/science/article/pii/S0360544202001391>.

[10] Manenti F, Adani F, Rossi F, Bozzano G, Pirola C. First-principles models and sensitivity analysis for the lignocellulosic biomass-to-methanol conversion process. Comput Chem Eng 2016;84:558-67. http://dx.doi.org/10.1016/ j.compchemeng.2015.05.012. <http://www.sciencedirect.com/science/article/ pii/S0098135415001647>.

[11] De Filippis P, Borgianni C, Paolucci M, Pochetti F. Prediction of syngas quality for two-stage gasification of selected waste feedstocks. Waste Manage 2004;24(6):633-9. http://dx.doi.org/10.1016/i.wasman.2004.02.014. <http:// www.sciencedirect.com/science/article/pii/S0956053X04000510>.

[12] Piatkowski N, Steinfeld A. Solar-driven coal gasification in a thermally irradiated packed-bed reactor. Energy Fuels 2008;22(3):2043-52. http://dx. doi.org/10.1021/ef800027c. wOS:000256057600086.

[13] Zeng K, Minh DP, Gauthier D, Weiss-Hortala E, Nzihou A, Flamant G. The effect of temperature and heating rate on char properties obtained from solar pyrolysis of beech wood. Bioresour Technol 2015;182:114-9. http://dx.doi. org/10.1016/j.biortech.2015.01.112.

[14] Piatkowski N, Wieckert C, Steinfeld A. Experimental investigation of a packedbed solar reactor for the steam-gasification of carbonaceous feedstocks. Fuel Process Technol 2009;90(3):360-6. http://dx.doi.org/10.1016/ i.fuproc.2008.10.007. <http://www.sciencedirect.com/science/article/pii/ S0378382008002671>

[15] Gordillo E, Belghit A. A downdraft high temperature steam-only solar gasifier of biomass char: a modelling study. Biomass Bioenergy 2011;35(5):2034-43. http://dx.doi.org/10.1016/i.biombioe.2011.01.051. www.sciencedirect.com/science/article/pii/S0961953411000663>.

[16] Belghit A. Etude théorique et expérimentale d'un gazéifieur solaire de matière carbonées en lit poreux mobile. PhD thesis. Université de Perpignan; 1986.

[17] Flechsenhar M, Sasse C. Solar gasification of biomass using oil shale and coal as candidate materials. Energy 1995;20(8):803-10. http://dx.doi.org/10.1016/ 0360-5442(95)00023-A. <http://www.sciencedirect.com/science/article/pii/ $036054429500023 \mathrm{~A}>$.

[18] Gordillo E, Belghit A. A bubbling fluidized bed solar reactor model of biomass char high temperature steam-only gasification. Fuel Process Technol 2011:92 (3):314-21. http://dx.doi.org/10.1016/i.fuproc.2010.09.021. <http:// www.sciencedirect.com/science/article/pii/S0378382010003218>.

[19] Li X, Grace J, Lim C, Watkinson A, Chen H, Kim J. Biomass gasification in a circulating fluidized bed. Biomass Bioenergy 2004;26(2):171-93. http://dx. doi org 101016/S0961-9534(03)00084-9. www.sciencedirect.com/science/article/pii/S0961953403000849>.

[20] Z'Graggen A, Steinfeld A. Hydrogen production by steam-gasification of carbonaceous materials using concentrated solar energy - V. Reactor modeling, optimization, and scale-up. Int J Hydrogen Energy 2008;33 (20):5484-92. http://dx.doi.org/10.1016/j.ijhydene.2008.07.047. <http:// www.sciencedirect.com/science/article/pii/S036031990800904X>.

[21] Piatkowski N, Wieckert C, Weimer AW, Steinfeld A. Solar-driven gasification of carbonaceous feedstock-a review. Energy Environ Sci 2011;4(1):73-82. http:// dx.doi.org/10.1039/c0ee00312c. wOS:000285748400006.

[22] Nzihou A, Flamant G, Stanmore B. Synthetic fuels from biomass using concentrated solar energy - a review. Energy 2012;42(1):121-31. http://dx. doi.org/10.1016/i.energy.2012.03.077. www.sciencedirect.com/science/article/pii/S0360544212002812>

[23] Chan W-CR, Kelbon M, Krieger BB. Modelling and experimental verification of physical and chemical processes during pyrolysis of a large biomass particle. Fuel 1985;64(11):1505-13. http://dx.doi.org/10.1016/0016-2361(85)90364-3. <http://www.sciencedirect.com/science/article/pii/0016236185903643>.

[24] Lédé J, Blanchard F, Boutin O. Radiant flash pyrolysis of cellulose pellets: products and mechanisms involved in transient and steady state conditions. Fuel 2002;81(10):1269-79. http://dx.doi.org/10.1016/S0016-2361(02)00039X. <http://www.sciencedirect.com/science/article/pii/S001623610200039X>.

[25] Di Blasi C, Branca C, Santoro A, Perez Bermudez RA. Weight loss dynamics of wood chips under fast radiative heating. J Anal Appl Pyrol 2001;57(1):77-90. http://dx.doi.org/10.1016/S0165-2370(00)00119-4. www.sciencedirect.com/science/article/pii/S0165237000001194>.

[26] Authier O, Ferrer M, Mauviel G, Khalfi A-E, Lede J. Wood fast pyrolysis: comparison of Lagrangian and Eulerian modeling approaches with 
experimental measurements. Ind Eng Chem Res 2009;48(10):4796-809. http://dx doi org/101021/ie801854c, wOS:000266081300016.

[27] Al-Haddad M, Rendek E, Corriou J-P, Mauviel G. Biomass fast pyrolysis: experimental analysis and modeling approach. Energy Fuels 2010;24 (9):4689-92. http://dx.doi.org/10.1021/ef901254g.

[28] Guesdon C, Alxneit I, Tschudi HR, Wuillemin D, Sturzenegger M. 1 kW imaging furnace with in situ measurement of surface temperature. Rev Sci Instrum 2006;77(3):035102. wOS:000236739100040.

[29] Llorente J, Ballestrin J, Vazquez AJ. A new solar concentrating system: description, characterization and applications. Sol Energy 2011;85 (5):1000-6. $\quad$ http://dx.doi.org/10.1016/i.solener.2011.02.018. wOS:000290644000029.

[30] Petrasch J, Coray P, Meier A, Brack M, Haeberling P, Wuillemin D, et al. A novel $50 \mathrm{~kW} 11,000$ suns high-flux solar simulator based on an array of xenon arc lamps. J Sol Energy Eng - Trans Asme 2007;129(4):405-11. http://dx.doi.org 10.1115/1.2769701. wOS:000250637900008.

[31] Codd DS, Carlson A, Rees J, Slocum AH. A low cost high flux solar simulator. Sol $\begin{array}{lll}\text { Energy } & 2010 ; 84(12): 2202-12 . \quad \text { http://dx.doi.org/10.1016 }\end{array}$ j.solener.2010.08.007. <http://www.sciencedirect.com/science/article/pii/ S0038092X10002665>

[32] Sarwar J, Georgakis G, LaChance R, Ozalp N. Description and characterization of an adjustable flux solar simulator for solar thermal, thermochemical and photovoltaic applications. Sol Energy 2014;100:179-94. http://dx.doi.org 10.1016/i.solener.2013.12.008. wOS:000331007700018.

[33] Pozzobon V, Salvador S. High heat flux mapping using infrared images processed by inverse methods: an application to solar concentrating systems. Sol Energy 2015;117C:29-35. http://dx.doi.org/10.1016/i.solener.2015.04.021.

[34] Langrish TAG, Keey RB, umar' M. Improving the quality of timber from red beech (n. Fosca) by intermittent drying. Drying Technol 1992;10(4):947-60. http://dx.doi.org/10.1080/07373939208916489.

[35] Cornelissen T, Yperman J, Reggers G, Schreurs S, Carleer R. Flash co-pyrolysis of biomass with polylactic acid. Part 1: Influence on bio-oil yield and heating value. Fuel 2008;87(7):1031-41. http://dx.doi.org/10.1016/i.fuel.2007.07.019. <http://www.sciencedirect.com/science/article/pii/S0016236107003419>.

[36] Demirbas A. Pyrolysis of ground beech wood in irregular heating rate conditions. J Anal Appl Pyrol 2005;73(1):39-43. http://dx.doi.org/10.1016 j.jaap.2004.04.002. <http://www.sciencedirect.com/science/article/pii S0165237004000889>

[37] Blasi CD. Dynamic behaviour of stratified downdraft gasifiers. Chem Eng Sci 2000;55(15):2931-44. http://dx.doi.org/10.1016/S0009-2509(99)00562-X. <http://www.sciencedirect.com/science/article/pii/S000925099900562X>.

[38] Xu Y, Li W, Hu X, Shi Y. Preparation and characterization of bio-oil from biomass. INTECH Open Access Publisher; 2011.
[39] Beaumont O, Schwob Y. Influence of physical and chemical parameters on wood pyrolysis. Ind Eng Chem Process Des Develop 1984;23(4):637-41.

[40] Pozzobon V, Salvador S, Bézian JJ, El-Hafi M, Le Maoult Y, Flamant G. Radiative pyrolysis of wet wood under intermediate heat flux: experiments and modelling. Fuel Process Technol 2014;128:319-30. http://dx.doi.org/ 10.1016/j.fuproc.2014.07.007. <http://www.sciencedirect.com/science/ article/pii/S0378382014

[41] Wongchang T, Patumsawad S, Fungtammasan B. An analysis of wood pyrolysis tar from high temperature thermal cracking process. Energy Sources Part A: Recov Util Environ Effects 2013;35(10):926-35. http://dx.doi.org/10.1080/ 15567036.2012 .707748$.

[42] Watanabe H, Morinaga Y, Okazaki K. Steam-reforming characteristics of heavy and light tars derived from cellulose. J Therm Sci Technol 2012;7(1):180-9. http://dx.doi.org/10.1299/itst.7.180. wOS:000305075400013.

[43] Damartzis T, Ioannidis G, Zabaniotou A. Simulating the behavior of a wire mesh reactor for olive kernel fast pyrolysis. Chem Eng J 2008;136(23):320-30. http://dx.doi.org/10.1016/j.cej.2007.04.010. <http:// www.sciencedirect.com/science/article/pii/S1385894707002550>.

[44] Gauthier G. Synthèse de biocarburants de deuxième génération: Etude de la pyrolyse à haute température de particules de bois centimétriques. $\mathrm{PhD}$ thesis. INPT EMAC; 2013.

[45] Agoua E, Perre P. Mass Transfer in wood: identification of structural parameters from diffusivity and permeability measurements. J Porous Media 2010;13(11):1017-24. wOS:000285561200008.

[46] Demirbas A. Determination of calorific values of bio-chars and pyro-oils from pyrolysis of beech trunkbarks. J Anal Appl Pyrol 2004;72(2):215-9. http://dx doi.org/10.1016/i.jaap.2004.06.005. <http://www.sciencedirect.com/science/ article/pii/S0165237004000610>.

[47] Mortensen PM, Grunwaldt JD, Jensen PA, Knudsen KG, Jensen AD. A review of catalytic upgrading of bio-oil to engine fuels. Appl Catal A: Gen 2011;407(12):1-19. http://dx.doi.org/10.1016/i.apcata.2011.08.046. <http:// www.sciencedirect.com/science/article/pii/S0926860X11005138>.

[48] Rabou L, van Leijenhorst R, Hazewinkel J. High efficiency power production from biomass and waste. ECN Biomass, Coal and Environmental Research; 2008. <https://www.ecn.nl/publications/E/2008/ECN-E-08-086>.

[49] Pavlas M, Stehlík P, Oral J, Klemeš J, Kim J-K, Firth B. Heat integrated heat pumping for biomass gasification processing. Appl Therm Eng 2010;30 (1):30-5. http://dx.doi.org/10.1016/j.applthermaleng.2009.03.013. <http:// www.sciencedirect.com/science/article/pii/S1359431109000957>.

[50] Ravaghi-Ardebili Z, Manenti F, Corbetta M, Pirola C, Ranzi E. Biomass gasification using low-temperature solar-driven steam supply. Renew Energy 2015;74:671-80. http://dx.doi.org/10.1016/j.renene.2014.07.021. <http://www.sciencedirect.com/science/article/pii/S0960148114004078>. 